\title{
Effect of Silicon Addition on Shock Consolidation of Diamond Powder and Microstructures in the Grain Boundaries
}

\author{
M. Ohkoshi, T. Akashi, K. Yamada ${ }^{\dagger}$, and A. B. Sawaoka \\ Materials and Structures Laboratory, Tokyo Institute of Technology, Midori, Yokohama, 226-8503, Japan \\ 'Sumitomo Coal Mining Co. Ltd., Akabira, Hokkaido, 079-1143, Japan \\ ${ }^{\dagger}$ Dept. of Chemistry, National Defense Academy, Yokosuka, Kanagawa 239-0811, Japan
}

\begin{abstract}
This paper describes results of shock recovery compaction experiments with a diamond / silicon composite powder. Under diamond compaction process, the addition of silicon causes to increase the hardness of recovered specimens. Because additive silicon reacts with diamond accompanying heat generation. This heat process contributes to reduction of micro and macro clack generation. The purpose of this study is to clarify the microstructure in the diamond compacts including silicon, and the effect caused by the addition method of silicon. By transmission electron microscopy (TEM) analysis, the boundary between diamond grains consist of amorphous carbon, graphite, silicon carbide and silicon. Silicon-carbite exist in the amorphous carbon layer as very fine particles.

[dynamic diamond compaction, composite powder compaction, microstructure of diamond / silicon compact]
\end{abstract}

\section{Introduction}

Since olden time, diamond is very attractive material not only for the value of jewels but also for industrial tools as cutting tips and drill bits, because diamond is the hardest of all known materials. But diamond crystals in general cleave easily, which is a disadvantage in application as drill bit for rock digging. Natural polycrystalline diamonds called carbonados [1, 2] or ballas [3], which possess isotropic mechanical properties and high fracture toughness. The size of most carbonados or ballas is less than $10 \mathrm{~mm}$. If large size of polycrystalline diamond could be manufactured industrially, their possible application could be extended to the drill bit material for rock excavators as well as cutting tools.

Two kinds of polycrystalline diamond synthesis methods are 1) static high pressure sintering techniques, and 2) shock consolidation techniques. Because diamond has a very small self-diffusion coefficient, it is required to obtain high density sinterd compact, very high temperature and pressure conditions. Thus it is quite difficult to synthesize diamond even when static high pressure technique is employed. Dynamic compaction technique seems to have greater potential for synthesizing polycrystal of a high pressure phase material like diamond. One of the serious problems on the shock consolidation of diamond powder is crack generation in the compact. Studies to eliminate crack were reported by Akashi and Sawaoka [4], Potter and Ahrens [5], and Sawai and Kondo [6], Hokamoto et al. [7], and so on. Akashi and Sawaoka developed a technique to control residual temperature by utilizing exothermic chemical reaction diamond with silicon or titanium as additive and succeeded to reduce the number of cracks generated. Because of crack decrease, the mechanical properties of the diamond compacts were improved.

The objective of this work is to clarify the microstructure of diamond grain boundaries in the diamond compacts including silicon, and the effect caused by the addition of silicon, which were (1) chemical vapor deposition and (2) mechanical mixing.

\section{Experimental}

Synthetic diamond powder provided by General Electric Co.,
Ltd. was used as the starting material for shock compaction experiment. The grain size was 2 to $4 \mu \mathrm{m}$ grade of GE-300 series.

Additive methods of silicon were used by means of plasma chemical vapor deposition (CVD) coating method, as shown in Fig. 1 and mechanical mixing. In the plasma CVD process, fine particles of silicon were deposited on the surface of starting diamond powder by plasma CVD-coating apparatus. In the second process, fine silicon powder, ranging under $0.1 \mu \mathrm{m}$, provided by Vacuum Metallurgical Co., Ltd. was mixed in ethylalcohol using an agate mortar. The silicon content of both mixtures was 7.0 vol.\%.

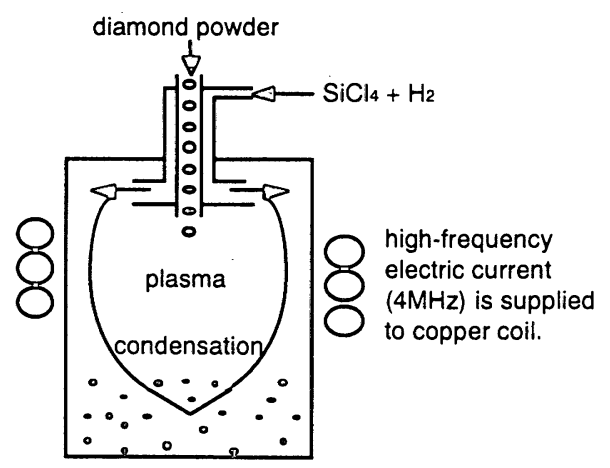

Fig. 1. Schematic of plasma CVD-coating apparatus

The composite powders were pressed into SUS-304 capsules to form disks of $5 \mathrm{~mm}$ thick and $12 \mathrm{~mm}$ in diameter ${ }^{\left[{ }_{1 / 3}\right.}$ under atmosphere of a nitrogen at the room temperature. The density of the pressed powders were $60 \%$ of theoretical.

Shock treatment was carried out with the use of a mousetrap type plane wave generator and a momentum trap recovery system, as shown in Fig. 2 [8]. The iron flyer plate of $3.2 \mathrm{~mm}$ thick was impacted at a velocity of $2.3 \mathrm{~km} / \mathrm{s}$ against capsules containing the composite powder. 
(a)
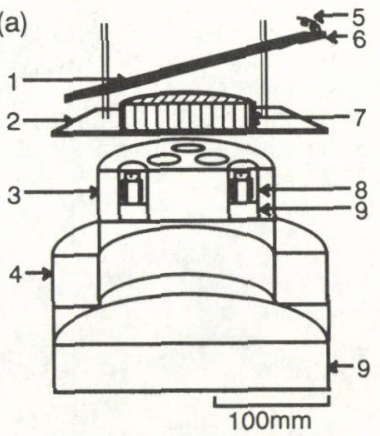

(b)

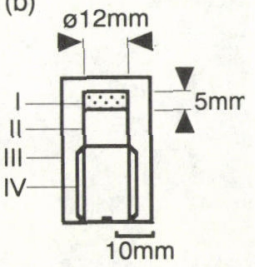

Fig. 2. Cross section of plane shock wave compaction fixture; (a) mouse-trap plane wave generator and momentum trap sample recovery system: [1. plane wave generator, 2 . iron flyer plate, 3. capsule holder, 4 . holder ring, 5 . detonator, 6 . line wave generator, 7. main explosive, 8. capsule, 9. momentum trap ]; (b) stainless steel capsule: [ I. sample, II. spacer, III. capsule, IV. plug ]

After the shock treatment, the samples in the form of disk were carefully taken out from recovered capsules using a lathe. Both the front and the rear face of the disks were grinded and polished, and then examined using X-ray diffraction (XRD) and subjected Vickers microhardness tests at a $9.8 \mathrm{~N}$ load for $10 \mathrm{~s}$. For microscopic characterization, the characterized specimens scraped from the region near the center on rear face, where the shock temperature and pressure were estimated to be the highest in samples, and transmission electron microscopy (TEM) was applied.

\section{Results and Discussions}

Table 1 gives the results of Vickers microhardness tests. The compact of diamond / silicon composite powder obtained by CVD technique has higher value of hardness than that by mechanical mixing.

Table 1. Summary of experimental conditions and results of Vickers microhardness test

\begin{tabular}{|c|c|c|c|c|c|c|}
\hline \multirow{2}{*}{$\begin{array}{l}\text { Impact } \\
\text { velocity } \\
{[\mathrm{km} / \mathrm{s}]}\end{array}$} & \multirow{2}{*}{$\begin{array}{l}\text { Diamond } \\
\text { grain size } \\
{[\mu \mathrm{m}]}\end{array}$} & \multirow{2}{*}{$\begin{array}{l}\text { Additive } \\
\text { of Si } \\
\text { [vol.-\%] }\end{array}$} & \multirow{2}{*}{$\begin{array}{l}\text { Additive } \\
\text { method } \\
\text { by }\end{array}$} & \multirow{2}{*}{$\begin{array}{l}\text { Initial } \\
\text { density } \\
{[\%]}\end{array}$} & \multicolumn{2}{|c|}{$\begin{array}{l}\text { Vickers hardness } \\
\text { [GPa] }\end{array}$} \\
\hline & & & & & Front & Rear \\
\hline 2.3 & $2-4$ & 7.0 & CVD & 60 & $28.5 \pm 11.0$ & $42.2 \pm 18.0$ \\
\hline 2.3 & $2-4$ & 7.0 & $\begin{array}{l}\text { mectkanical } \\
\text { mixing }\end{array}$ & 60 & $23.7 \pm 5.0$ & $27.2 \pm 9.0$ \\
\hline
\end{tabular}

Fig. 3 shows transmission electron micrographs of composite powder obtained by (a) CVD technique and (b) mechanical mixing, respectively. In the composite powder by CVD technique, the additive silicon was distributed homogeneously than in that by mechanical mixing. However small amount of silicon aggregates existed even in the composite powder by CVD technique, and the peaks of non-reacted silicon were found in XRD patterns of both compacts obtained after the shock treatment.

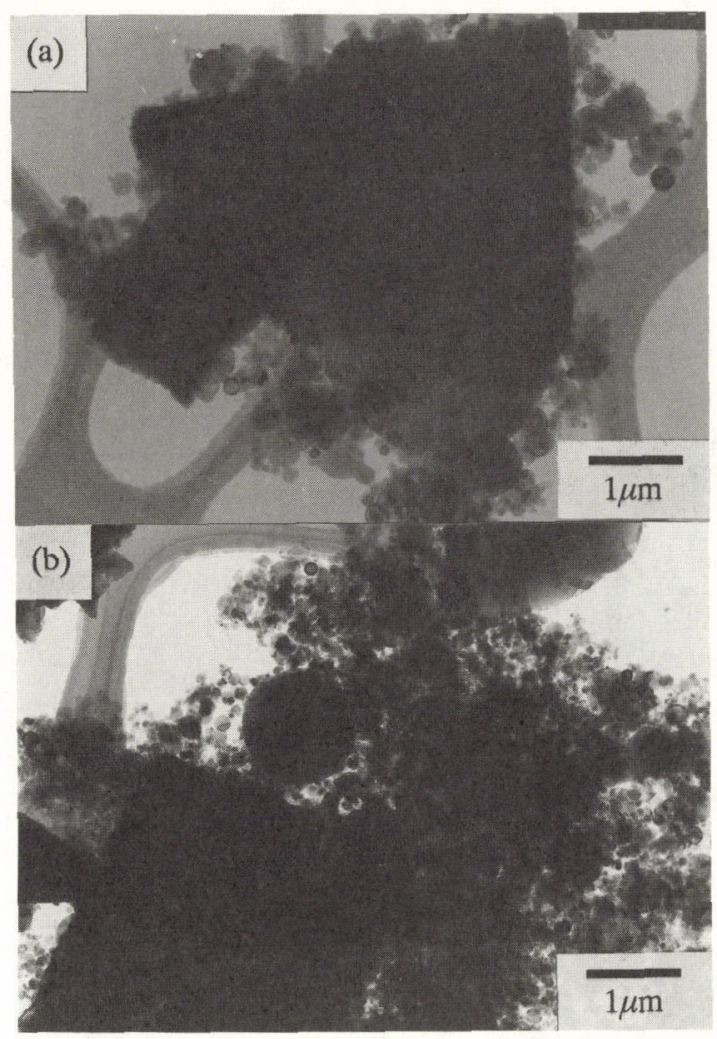

Fig. 3. TEM image of composite powders before shock loading obtained by (a) CVD technique and (b) mechanical mixing.

Microstructure observation was conducted by TEM. Fig. 4 . (a) shows diamond particles in the recovered samples after shock treatment and Fig. 5 shows lattice image in diamond grain boundary. It is suggested by electron diffraction observation as shown in Fig. 5 that i correspond to $\alpha-\mathrm{SiC}, \mathrm{j}$ to diamond, $\mathrm{k}$ to diamond, $\alpha-\mathrm{SiC}$ and amorphous carbon, 1 to diamond, respectively. It was observed that diamond particles were crushed to small grains by shock loading, as shown in Fig. 4. (a) and (b). In addition, it was found that grain boundaries consisted of amorphous carbon transformed from diamond, where the silicon carbide with very fine particle size dispersed in. The size of silicon carbide particles as inclusions in the surface region of the diamond particles, ranged under $50 \mathrm{~nm}$.

It was assumed that this nano composite structure was formed through four steps, as described below. (i) Compression of particles accompanied with friction, cracking and reduction of particles size, caused by the passage shock wave, (ii) locally melting of diamond particle surface and additive silicon due to high shock temperatures, (iii) string and mixing in melted surface of diamond caused by friction and jetting effect, (iv) rapid cooling and quenching of the liquid region due to high thermal heat conductivity of the diamond particles. It was considered that step (iii) contributed to formation of amorphous carbon layer included fine $\mathrm{SiC}$ particle. 

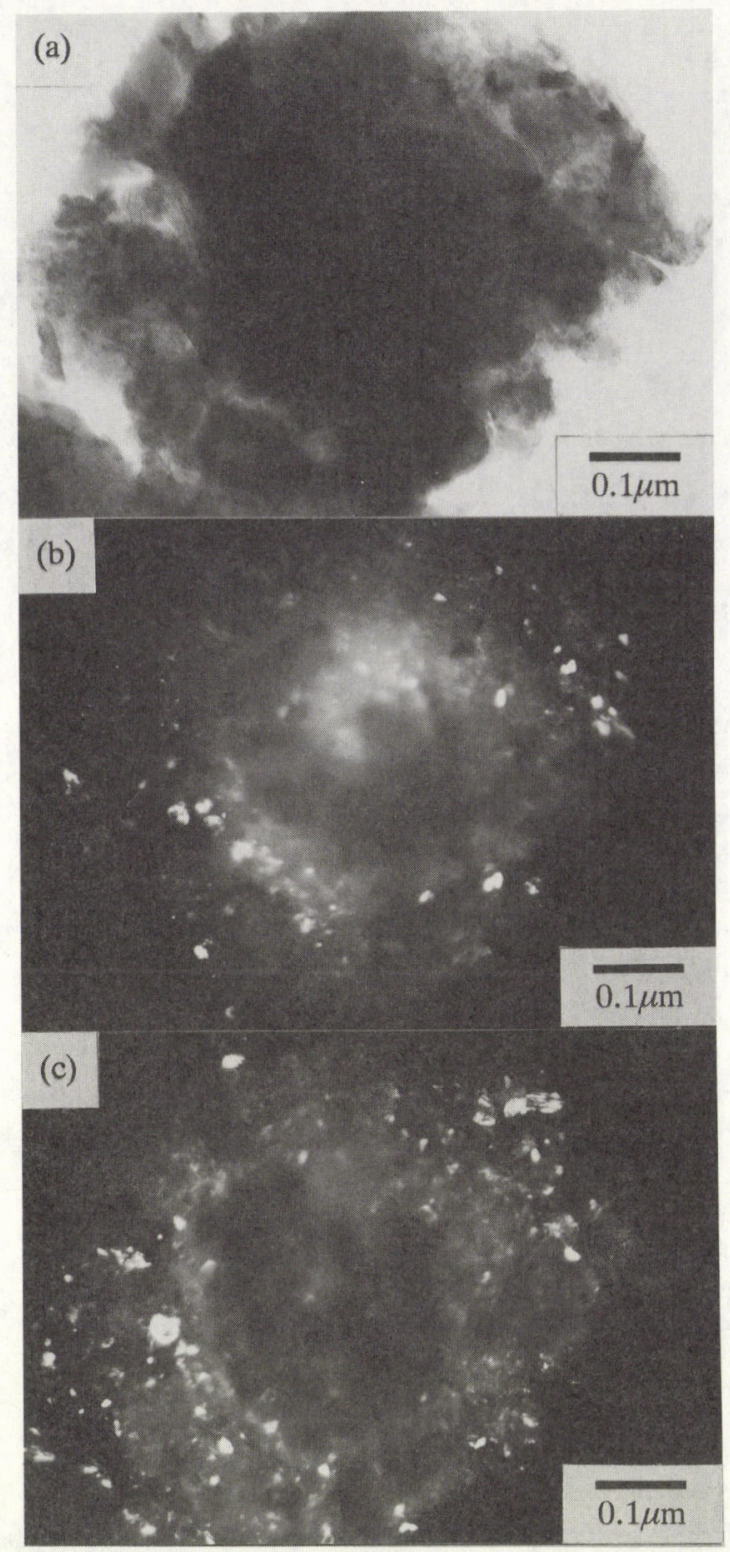

Fig. 4. TEM Image of the inner region near the center on rear face in the compact, obtained from dia / Si powder by CVD. (a) Blight-field image, (b) Dark-field image of dia (111) in Fig. 4 (a) and (c) Dark-field image of $\alpha-\mathrm{SiC}$ (111) in Fig. 4 (a).

On the other hand, it was found that non-reacted silicon remained in the shock treated compacts and silicon aggregates in the composite powders reacted with diamond and formed coarse particles of $\mathrm{SiC}$ in recovered compacts. This tendency is remarkable in the compacts obtained from mechanical mixing than CVD technique.

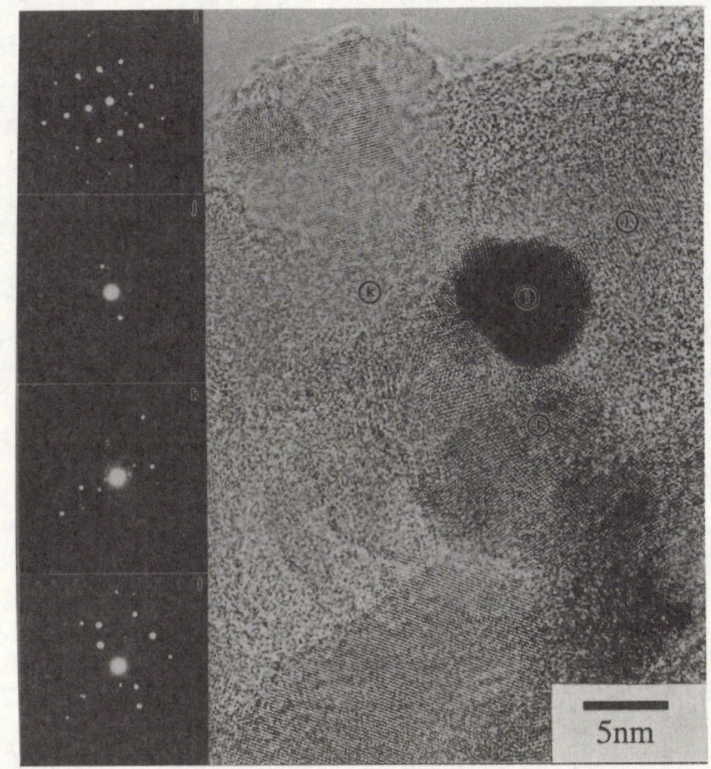

Fig. 5. Lattice image of diamond grain boundary given detail in Fig. 4 (a) and the EDP in i correspond to analysis of area (i), the EDP in $\mathrm{j}$ to (1), the EDP in $\mathrm{k}$ to $(\mathbb{k}$, and the EDP in 1 to (1).

\section{Conclusions}

Microstructures in the grain boundaries obtained by shock compaction of the diamond / silicon composite powders were investigated. In the shock treated compacts, additive silicon existed in amorphous carbon layer transformed from diamond, as the fine particle of $\mathrm{SiC}$. It is expected that this nano composite structure contributed to improvement of mechanical property of the compacts.

It seems that silicon aggregates in the composite powder obtained by mechanical mixing cause formation of coarse $\mathrm{SiC}$ particles. Major reason of lower hardness of the compact obtained from mechanical mixed composite powder might be unhomogeneous dispersion of coarse $\mathrm{SiC}$ particles. Therefore, improvement for homogeneous dispersion of additive is important theme for practical application of shock processing of diamond powders, and could expect to obtain the good quality of synthesis diamond compact.

\section{References}

[1] L.F.Trueb and W.C.Butterman, Am.Mineralogist, 54, 412 (1969).

[2] Y.Moriyoshi, M.Kamo, N.Setaka, and Y.Sato, J.Mater.Sci., 18, 217 (1983).

[3] L.F.Trueb and C.S.Barrett, ibid, 57, 1664 (1972).

[4] T.Akashi and A.B.Sawaoka, J.Mater.Sci., 22, 3276 (1987).

[5] D.K.Potter and R.Ahrens, J.Appl.Phys., 63, 910 (1988).

[6] K.Kondo and S.Sawai, J.Am.Ceram.Soc., 73, 1983 (1990).

[7] K.Hokamoto, S.S.Shang, L.H.Yu, and M.A.Meyers, Shockwave and high-strain-rated in materials, 453 (1992).

[8] A.B.Sawaoka, M.Takamatsu, and T.Akashi, Adv.Mater., 6, 346 (1994). 